Forthcoming in William J. Devlin and Alisa Bokulich (eds.) (2015), Kuhn's Structure of Scientific Revolutions - 50 Years On. Boston Studies in the Philosophy and History of Science, vol. 311. Springer.

\title{
Reconsidering the Carnap-Kuhn Connection
}

\author{
Jonathan Y. Tsou
}

Department of Philosophy and Religious Studies, Iowa State University

\begin{abstract}
:
Recently, some philosophers of science (e.g., Gürol Irzik, Michael Friedman) have challenged the 'received view' on the relationship between Rudolf Carnap and Thomas Kuhn, suggesting that there is a close affinity (rather than opposition) between their philosophical views. In support of this argument, these authors cite Carnap and Kuhn's similar views on incommensurability, theory-choice, and scientific revolutions. Against this revisionist view, I argue that the philosophical relationship between Carnap and Kuhn should be regarded as opposed rather than complementary. In particular, I argue that a consideration of the fundamentally disparate nature of the broader philosophical projects of Carnap (logic of science) and Kuhn (providing a theory of scientific revolutions) renders the alleged similarities between their views superficial in comparison to their fundamental differences. In defense of the received view, I suggest that Carnap and Kuhn are model representatives of two contrasting styles of doing philosophy of science, viz., logical analysis and historical analysis respectively. This analysis clarifies the role played by Kuhn's Structure of Scientific Revolutions in the demise of logical empiricism in the second half of the twentieth-century.
\end{abstract}

KEYWORDS: Rudolf Carnap; Thomas Kuhn; History of twentieth century philosophy of science; Philosophy of science methodology; Incommensurability; Instrumentalism; Scientific revolutions; context of discovery/ context of justification 


\section{Introduction}

Rudolf Carnap (1891-1970) and Thomas Kuhn (1922-1996) are undoubtedly two of the most influential twentieth-century philosophers of science. According to the 'received view' on the Carnap-Kuhn relationship, Carnap's and Kuhn's views represent diametrically opposed approaches to philosophy of science and Kuhn's ([1962] 1996) Structure of Scientific Revolutions is one of the main philosophical works — along with Quine's ([1951] 1980) “Two Dogmas of Empiricism"- that (rightfully) contributed to demise of logical empiricism in the 1960s and 1970s. While the received view has been commonplace among post-positivist philosophers of science (e.g., see Suppe [1974] 1977; Giere 1988, ch. 2; McGuire 1992), this narrative about the history of philosophy of science has been increasingly called into question in recent decades.

Some historians of philosophy of science (Reisch 1991; Earman 1993; Irzik and Grünberg 1995; Friedman 2001, 2003; Irzik 2002, 2003; Richardson 2007; Gattei 2008, ch. 5; Uebel 2011) have argued that the received view on Carnap and Kuhn is mistaken, suggesting that there is a close affinity between their philosophical views. The basis for this revised understanding stems from some fundamental similarities between the philosophical systems of Carnap and Kuhn, especially on issues concerning incommensurability, theory-choice, and the nature of scientific revolutions. The upshot of this revisionist picture is that the "two styles of doing philosophy of science epitomized by Carnap and Kuhn should be seen as complementary rather than mutually exclusive" (Irzik and Grünberg 1995, pp. 304-305). Furthermore, some revisionists have drawn the more radical conclusion that this revised understanding on the relationship between Carnap and Kuhn "undermines the widely held belief that post-positivist 
philosophy of science represents a revolutionary departure from its arch-rival positivism, at least in the context of Carnap's and Kuhn's works" (Irzik and Grünberg 1995, p. 304).

In this paper, I argue against the revisionist conclusion that Carnap's and Kuhn's philosophical views are closely aligned; moreover, I reject the revisionist idea that Kuhn's philosophical views do not represent a revolutionary departure from Carnap's. ${ }^{1}$ While there are undoubtedly similarities between Carnap's and Kuhn's philosophical systems, I argue that a consideration of their broader philosophical projects renders these similarities superficial in comparison to their fundamental differences. On a general level, revisionist analyses fail to sufficiently acknowledge that Carnap's linguistic frameworks are logical reconstructions intended to clarify answerable (i.e., meaningful) and unanswerable (i.e., meaningless) questions, while Kuhn's theory of scientific revolutions is motivated to provide a naturalistic description of scientific change. This difference reflects two vastly different styles of doing philosophy of science (viz., logical analysis versus historical analysis). On a more specific level, I argue that Carnap's stance on incommensurability is far less robust than Kuhn's, Carnap holds a more instrumentalist position on theory-choice than Kuhn, and Carnap's analysis of revolutions is antithetical to Kuhn's. From this perspective, I suggest that the methodologies of Carnap and Kuhn are correctly regarded as two contrasting philosophical styles that mark a significant division between positivist and post-positivist philosophy of science.

\footnotetext{
${ }^{1}$ At the outset, it is important to note that there is variability among how strongly (and how qualified) the revisionist thesis is advanced by various authors. Moreover, different revisionist analyses have been forwarded for various purposes, e.g., Friedman's $(2001,2003)$ analysis is motivated to demonstrate a shared neo-Kantian heritage inherited by Carnap and Kuhn (see DiSalle 2002; Richardson 2002; Tsou 2003; Lange 2004). The main target of the argument in this paper is Gürol Irzik and Teo Grünberg's (1995) influential article, "Carnap and Kuhn: Arch Enemies or Close Allies?," which offers one of the strongest expressions of the revisionist view. While my argument focuses on Irzik and Grunberg's (1995) article, it is more broadly applicable to other revisionist analyses that, either explicitly or implicitly, follow a similar line of reasoning.
} 


\section{The Revisionist View}

The basis for the revisionist view stems from parallels in Kuhn's theory of scientific revolutions and Carnap's philosophy of linguistic frameworks (Friedman 2001, pp. 41-43, 2003, pp. 20-22; Richardson 2007, pp. 354-356). Kuhn's claim that the solution to scientific puzzles is provided by the tacit rules of a paradigm is similar to Carnap's ([1950] 1956) claim that answers to meaningful (internal) questions are provided by the rules of a linguistic framework. Moreover, just as Kuhn maintains that there are no clearly defined (algorithmic) rules for choosing among competing paradigms, Carnap holds that there is no cognitively significant (i.e., meaningful) way of choosing among alternative linguistic frameworks. On this issue, both Kuhn and Carnap maintain that these decisions must be made on non-epistemic grounds. For revisionists, these similarities suggest a significant point of agreement between Carnap and Kuhn grounded in "a pragmatically oriented semantic conventionalist picture of science” (Irzik and Grünberg 1995, p. 285).

Revisionists contend that both Carnap and Kuhn endorse a version of the incommensurability thesis (Irzik and Grünberg 1995; Irzik 2002; Richardson 2007, pp. 356-357). Incommensurability is central to Kuhn's ([1962] 1996, chs. 9-10) idea that competing paradigms are incompatible to the extent that proponents of competing paradigms cannot communicate with one another since their theoretical and epistemic commitments preclude them from comprehending alternative views. In Structure (Kuhn [1962] 1996), incommensurability variably refers to the incompatibility of problems and standards (p. 103, pp. 148-149), meaning (pp. 101103, p. 149), and perception (p. 112, p. 150). In post-Structure writings, Kuhn (2000) offers a more precisely defined thesis of 'local incommensurability' in terms of untranslatability: “The claim that two theories are incommensurable is . . the claim that there is no language, neutral or 
otherwise, into which both theories, conceived as sentences, can be translated without residue or loss" (p. 36). To support the idea that Carnap endorses a similar thesis, Irzik and Grünberg (1995, pp. 291-295) point to Carnap's ([1936] 1949) claim that competing linguistic frameworks are sometimes untranslatable:

In translating one language into another the factual content of an empirical statement cannot always be preserved unchanged. Such changes are inevitable if the structures of the two languages differ in essential points. ... [W]hile many statements of modern physics are completely translatable into statements of classical physics, this is not so ... when the statement ... contains concepts (like, e.g., 'wave-function' or 'quantization') which simply do not occur in classical physics ... [T] hese concepts cannot be ... included since they presuppose a different form of language. (p. 126)

Irzik and Grünberg (1995) contend that this 'semantic untranslatability' thesis is essentially the same as Kuhn's local meaning incommensurability thesis and Carnap's endorsement of this thesis follows from his commitment to a semantic holism (i.e., that the theoretical postulates of a linguistic framework determine the meaning of theoretical terms in $L$ ) similar to Kuhn's holism (pp. 291-293).

Other revisionists emphasize that both Carnap and Kuhn maintain that choosing between competing scientific theories is a non-epistemic and pragmatic matter (Friedman 2001, pp. 4143; 2003, pp. 19-21). ${ }^{2}$ In Carnap's philosophy, this stance is explicit in the understanding of

\footnotetext{
${ }^{2}$ Gürol Irzik (2003) has argued — correctly, in my judgment—against this specific claim. In particular, Irzik opposes "relativist" interpretations of Carnap and Kuhn (e.g., see Friedman, 1998, 2001), suggesting that both Carnap and Kuhn hold nuanced views on scientific rationality that are not accurately described as "relativist" (cf. Axtell 1993; Irzik 2003, pp. 331-335).
} 
external questions as practical proposals to adopt a particular linguistic framework. Carnap ([1950] 1956) writes:

[T] he introduction of [a new linguistic framework] does not need any theoretical justification because it does not imply any assertion of reality. . [W]e have to face at this point an important question; but it is a practical, not a theoretical question ... of whether or not to accept the new linguistic forms. The acceptance cannot be judged as true or false because it is not an assertion. It can only be judged as being more or less expedient, fruitful, conducive to the aim for which the language is intended. (p. 214)

For Carnap, choosing a linguistic framework only implies a commitment to a particular way of speaking. Since linguistic frameworks can be employed for different purposes, Carnap believes that they should be evaluated as instruments for various ends, rather than by their 'correctness.' In the spirit of the 'principle of tolerance,' Carnap recommends a permissive and pluralistic attitude towards different linguistic forms (Carnap [1934] 1937, §17; [1950] 1956, p. 221; Jeffrey 1994). Kuhn ([1962] 1996, pp. 94-110, pp. 198-207; 1977; 2000, ch. 9) adopts a similar stance on the non-epistemic nature of theory-choice insofar as he argues that choosing between competing paradigms is a process that cannot be settled in terms of 'correctness.' Kuhn (1977) emphasizes that in comparing the relative merits of competing paradigms, scientists typically appeal to a set of fixed-values (e.g., empirical adequacy, consistency, explanatory scope, simplicity); however, when applying these values, proponents of different paradigms will interpret and place different weights on these values. Hence, there is no objective (i.e., shared) set of values that can be appealed to in theory choice, which necessarily involves appeals to subjective factors. Insofar as Kuhn holds that there is no truly objective (or intersubjective) basis 
for paradigm choice, he endorses the Carnapian view that theory-choice is ultimately nonepistemic and pragmatic.

Revisionists also suggest that Kuhn and Carnap share a similar view of scientific revolutions (Reisch 1991; Irzik and Grünberg 1995; Friedman 2001, p. 22, pp. 41-42; Irzik 2002). Kuhn ([1962] 1996, chs. 9-10) famously rejects the view that scientific change is continuous and cumulative. In his model, scientific change proceeds through repeated cycles of normal science and revolutionary science. Whereas normal science is a cumulative period of puzzle-solving, revolutionary science is characterized by an older paradigm being replaced (in whole or in part) by an incommensurable new one. Hence, Kuhnian revolutions are neither rulegoverned nor cumulative, which opposes the putative view that scientific change is progressive and cumulative. Revisionists suggest that Carnap endorses a similar view of revolutions. In discussing how scientists respond to anomaly (a Quinean 'recalcitrant experience'), Carnap (1963) summarizes his view of revolutions as follows: "[A] change in the language ... constitutes a radical alteration, sometimes a revolution, and it occurs only at certain historically decisive points in the development of science.... A change of [this] kind constitutes, strictly speaking, a transition from a language $L_{n}$ to a new language $L_{n+1}$ " (p. 921). Given Carnap's views on semantic untranslatability and the pragmatic nature of theory choice, the transition from one linguistic framework to another is a process governed by pragmatic factors, and hence, discontinuous and non-cumulative. 


\section{A Problem with the Revisionist View}

While the revisionist view reveals some interesting similarities between Carnap's and Kuhn's philosophical views, when Carnap's and Kuhn's views are examined in the context of their broader philosophical projects, these similarities turn out to be superficial rather than substantial. Revisionist analyses articulate their arguments by framing Carnap's views in Kuhnian terminology, such as 'paradigms,' 'incommensurability,' and 'scientific revolutions.' Moreover, they suggest that Carnap's linguistic frameworks can be understood as an analogue (or formal complement) to Kuhn's paradigms (in the sense of 'disciplinary matrices'). This exegetical perspective, however, obscures the fundamentally disparate nature of the broader philosophical projects of Carnap and Kuhn. In particular, it fails to sufficiently acknowledge that Carnap's linguistic frameworks are artificial languages that scientific philosophers construct for purposes of logical analysis, while Kuhn's paradigms are conceived of naturalistically, as a constellation of commitments (i.e., symbolic generalizations, metaphysical models, values, exemplars) shared by a community of scientists. Framing Carnap's linguistic frameworks as analogues to Kuhn's paradigms brings Carnap's philosophical project closer to Kuhn's agenda of providing an accurate historical description actual scientific practices and theories; however, it does so at the expense of obscuring the fundamental nature and aims of Carnap's philosophy. In what follows, I explicate the nature of Carnap's logic of science program to motivate an argument that the fundamental differences between Carnap's and Kuhn's broader philosophical projects render the similarities that revisionists highlight superficial.

The proper context for understanding Carnap's philosophy of linguistic frameworks is Carnap's "logic of science" (Wissenschaftslogik), which is Carnap's proffered replacement for 'epistemology' or 'philosophy' more generally (see Richardson 1998, ch. 9). In the forward to 
Logical Syntax of Language, Carnap ([1934] 1937) presents logic of science as a scientific philosophy characterized by logical analysis:

That part of the work of philosophers which may be held to be scientific ... consists of logical analysis. The aim of logic of science is to provide a system of concepts, a language, by the help of which the results of logical analysis will be exactly formulable. Philosophy is to be replaced by the logic of science - that is to say, by the logical analysis of the concepts and sentences of the sciences, for the logic of science is nothing other than the logical syntax of language. (p. xiii, emphasis in original)

According to Carnap, the task of scientific philosophers is to logically analyze scientific concepts and sentences. This methodological prescription is motivated to ensure meaningful discourse about science. Carnap believes that modern logic provides the necessary tools to transform (or translate) formerly metaphysical problems into meaningful problems. In "Unity of Science," Carnap ([1931] 1934) rejects the traditional fields of philosophy (i.e., metaphysics, epistemology, and ethics), and he describes the problems of scientific philosophy as follows:

[O]ur own field of investigation is that of Logic. Here are to be found problems of ... the Logic of Science, i.e., the logical analysis of the terms, statements, theories, proper to the various department [s] of science. Logical Analysis of Physics, for example, introduces the problems of Causality, of Induction, of Probability, the problem of Determinism ... [as] question[s] concerning the logical structure of the systems of physical laws, in divorce from all metaphysical questions .... Logical Analysis of Biology, again, involves the problems of Vitalism, to take one example ... in a form free from Metaphysics, viz. as a question of the logical relations between biological and physical terms and laws .... In Psychology, Logical Analysis involves, among others the so 
called problem of the 'relation between Body and Mind' ... concerned ... with the logical relations between the terms or laws of Psychology and Physics respectively .... In all empirical sciences, finally, Logical Analysis involves the problem of verification . . . as a question concerning the logical inferential relations between statements in general and so called protocol or observation statements. (pp. 24-25, emphasis added)

As indicated in the last sentence of this passage, Carnap maintains that logic of science is especially concerned with the problem of "verification" or "confirmation," which is an aspect of Carnap's philosophy that is consistently neglected by revisionists. ${ }^{3}$ For the purposes of this paper, I want to highlight the deflationary nature of logic of science and indicate how it relates to the problem of meaningfulness. By reformulating and reconstructing scientific theories into purely logical (i.e., syntactic and semantic) systems or linguistic frameworks, Carnap believes that meaningful discourse about science can be ensured by clarifying the empirical basis of scientific theories (see Dempoulos 2003, 2007). In the case of sciences such as physics and biology, this amounts to translating metaphysical problems into empirically ascertainable ones.

One of the main tasks of logic of science is to develop an exact and objective method (the method of 'logical syntax') for discussing scientific propositions. For Carnap ([1934] 1937), the "important thing is to develop an exact method for the construction of . . sentences about sentences" (p. xiii, emphasis added). The logical syntax of a language is simply the "formal theory of linguistic forms of that language — the systematic statement of formal rules which govern it together with the development of the consequences which follow from these rules" (ibid, §1). By reconstructing a language into its syntax, Carnap believes that one can specify the

\footnotetext{
${ }^{3}$ Carnap's preoccupation with these issues is most clearly represented in his various (and increasingly deflationary) attempts at articulating an empiricist criterion of meaningfulness (see Carnap [1931] 1959; 1936; 1937; 1956; Hempel 1965).
} 
rules of a language. Carnap proposes to construct sentences about sentences by constructing two languages: (1) the object-language, which is the language that is the object of investigation (e.g., a scientific theory), and (2) the syntax-language (or meta-language), which is the language used to speak about the object-language. Carnap (ibid, §§78-81) believes that confusion occurs when philosophers speak within an object-language (the so-called material mode of speech) without recognizing that these assertions are made within or relative to an object-language. For Carnap, the meta-language (the formal mode of speech) - the perspective that reconstructs sentences and concepts of the object language syntactically—is the proper (and metaphysically neutral) philosophical perspective for evaluating these sentences, not as assertions, but as proposals to use a linguistic framework.

Given the nature and aims of logic of science, it is important to see that revisionists employ a self-serving exegetical strategy when they frame Carnap's philosophy of linguistic frameworks in Kuhnian terms. In particular, it is mistaken to regard Carnapian linguistic frameworks as straightforward analogues (or even formal complements) to Kuhnian paradigms. This interpretation is suggested by phrases like "every scientific theory is embedded within a linguistic framework" (Irzik 2002, p. 607); "a shift from one linguistic framework to another is a revolution" (Irzik and Grünberg 1995, p. 295); or "[p]aradigms, like linguistic frameworks, constitute the conditions of scientific knowledge - scientific knowledge-making only unproblematically occurs when a paradigm is in hand" (Richardson 2007, p. 336). These characterizations suggest that Carnapian linguistic frameworks can be understood as akin to Kuhnian paradigms, i.e., as a historically-situated set of commitments and assumptions that function to bind scientific communities (cf. Irzik and Grünberg 1995, p. 286). This understanding, however, inverts Carnap's philosophy of linguistic frameworks. Carnapian 
frameworks are not (temporally or logically) prior to scientific theories, but theories are prior to linguistic frameworks insofar as the latter are logical reconstructions of scientific theories, which are formulated to clarify the meaningful basis of theories. Conversely, from a naturalistic perspective, Kuhn ([1962] 1996, ch. 5) regards paradigms as (temporally and logically) prior to scientific rules and theories. ${ }^{4}$ This subtle difference highlights a significant contrast between Kuhnian paradigms (i.e., a cluster of shared commitments that are necessary for normal science) and Carnapian linguistic frameworks (i.e., formal reconstructions of scientific theories). While revisionists are well aware of the artificial nature of linguistic frameworks (Irzik and Grünberg 1995, p. 288; Friedman 1999, ch. 9; Richardson 1998, ch. 9), when they argue for similarities between Carnap and Kuhn, they obscure the nature of Carnap's linguistic frameworks by presenting them in a Kuhnian light. ${ }^{5}$

\section{Logical Analysis vs. Historical Analysis}

Differences in Carnap's and Kuhn's methodological assumptions reflect two radically contrasting styles of doing philosophy of science. In the following section, I dub these two styles

\footnotetext{
${ }^{4}$ In chapter 5 of Structure ("The Priority of Paradigms"), Kuhn argues that it is paradigms (rather than explicit rules) that determine the nature of normal science. Kuhn suggests that paradigms are prior to rules in a temporal sense (i.e., paradigms will suggest certain rules, but not in a determinate way), but also in terms of importance (i.e., paradigms are more important than the rules that are abstracted from the paradigm for binding a community of scientists during normal science). On the basis of these considerations, Kuhn suggests that philosophers of science ought to focus their attention on paradigms (i.e., exemplars), as a unit of analysis, rather than explicit rules. It is important to notice that Kuhn's methodological prescription is opposed to Carnap's attempt to reduce scientific theories to a set of explicit rules (e.g., syntax). Moreover, the tacit rules discussed by Kuhn are not the same kinds of rules at the core of Carnap's linguistic frameworks (Pincock 2012, pp. 127-128).

${ }^{5}$ From a somewhat different perspective, Peter Galison (1995) suggests that Kuhnian paradigms and Carnapian linguistic frameworks are similar insofar as they represent science in terms of "island empires," i.e., isolated and relatively stable assemblages of experimental and theoretical procedures and results. Galison opposes this island empire picture of science because it conceals the fragmented and heterogeneous nature of science.
} 
logical analysis and historical analysis, and I articulate the assumptions of these fundamentally disparate ways of doing philosophy of science. In the context of the revisionist argument, this shows that there are good reasons for regarding Carnap's and Kuhn's views as standing in an antagonistic, rather than complementary, relationship.

The most fundamental difference between Carnap's and Kuhn's styles of doing philosophy of science is their methodological approaches to analyzing scientific theories. For Carnap, logical analysis assumes that scientific theories should be analyzed only after they have been reconstructed into artificial linguistic frameworks, which scientific philosophers can investigate in the formal mode of speech. Kuhn's approach, by contrast, assumes that theories should be analyzed after they have been historically reconstructed as paradigms or lexicons. The key difference in Kuhn's approach is that paradigms are treated and analyzed, not as artificial languages, but as naturalistic entities, i.e., as accurate descriptions of scientific theories. ${ }^{6}$ Hence, Kuhnian philosophy of science is concerned with accurately reconstructing scientific theories and practices with the aid of a posteriori sciences such as history and psychology (see Giere 1985; Bird 2002, 2004; Preston 2004). This naturalistic aspect of Kuhn's approach is entirely absent in Carnap's. Whereas accurate historical reconstruction, for Kuhn, is crucial for proper philosophical analysis, Carnap is only concerned with accurate reconstruction to the extent that it

\footnotetext{
${ }^{6}$ As a qualification, Kuhn's naturalistic approach was most marked in Structure, and in his post-Structure writings, Kuhn took a 'linguistic turn' wherein his work became more traditionally philosophical and relied less heavily on the history of science (see Irzik \& Grünberg 1998; Bird 2000, 2002, 2004; Kindi 2005; Mladenović 2007; Gattei 2008). In offering a qualified defense of the received view on the Carnap-Kuhn relationship, my claim is that Kuhn's early philosophical views - as exemplified in Structure - are significantly different than the style of philosophy of science championed by Carnap. While Irzik and Grünberg (1995) focus on Kuhn's later work in advancing their argument that Carnap and Kuhn are 'close allies,' I focus on Kuhn's early views because: (1) Kuhn's Structure was much more influential and widely read by philosophers of science than his later works, and (2) Kuhn's Structure is the most relevant work for the received view on the Carnap-Kuhn relationship that maintains that Kuhn contributed to the demise of logical empiricism by offering a revolutionary approach to philosophy of science (discussed in $\S 4$ of this paper).
} 
allows him to distinguish theories into their observational and theoretical parts, which will clarify the sense in which theories are cognitively significant.

Carnap and Kuhn also adopt contrasting stances on the context of discovery and context of justification distinction (Pinto de Oliveira 2007; cf. Uebel 2011). Whereas Carnap assumes a sharp distinction (given that logic of science occurs exclusively in the context of justification), Kuhn believes that there is no sharp distinction and that issues concerning the justification of scientific theories cannot be analyzed in isolation from issues regarding the discovery of those theories (Kuhn [1962] 1996, pp. 8-9, pp. 207-208). Carnap's ideal of rationally reconstructing scientific theories into linguistic frameworks assumes that the philosopher can investigate questions concerning the justification of scientific theories via logical analysis by clarifying which parts of the theories are empirically ascertainable. Issues concerning the justification of theories for Kuhn are more complex. ${ }^{7}$ In response to questions concerning whether his theory is descriptive or prescriptive (e.g., see Feyerabend 1970), Kuhn ([1962] 1996, pp. 207-208; 2000, p. 130) argued that descriptive generalizations from the history of science can sometimes serve as evidence for philosophical prescriptions. This aspect of Kuhn's philosophy highlights the way in which his approach rejects the discovery/ justification distinction and takes actual scientific practices seriously. Whereas Carnapian logical analysis takes reconstructed artificial linguistic frameworks (removed from the context of discovery) as the proper unit of philosophical analysis, Kuhnian historical analysis takes actual scientific theories and practices to be the proper unit of analysis (from which prescriptive claims can subsequently be inferred). Whereas Carnap's philosophical system prescribes certain scientific standards a priori (e.g., theories should be nonmetaphysical and empirically meaningful), Kuhn's philosophy takes a more a posteriori

\footnotetext{
${ }^{7}$ For a more comprehensive discussion of Kuhn's views on the discovery-justification distinction, see HoyningenHuene (1993, pp. 245-252; 2006).
} 
approach insofar as it examines historical cases of science to address questions concerning what constitutes good science.

These differences in Carnap's and Kuhn's approaches demonstrate why it is misleading to suggest that their philosophical views are similar on issues of incommensurability. Whereas incommensurability, for Carnap, is a trivial fact about certain reconstructed linguistic frameworks (e.g., quantum mechanics cannot be fully reconstructed into the terms of classical mechanics), for Kuhn, incommensurability is a substantive conclusion that he reaches through historical analysis. A central aspect of Kuhn's thesis is that proponents of competing paradigms 'work in different worlds' and cannot fully communicate with one another. This aspect of Kuhnian incommensurability is entirely antithetical to the spirit of Carnap's logic of science. Logic of science is motivated precisely to resolve scientific debates by clarifying which disagreements are amenable to meaningful resolution, and which are merely pragmatic. As Carnap consistently reported, he was dismayed by fruitless metaphysical debates and logic of science is a method for resolving these debates. Hence, incommensurability is a substantive conclusion reached by Kuhn (via historical analysis), while it is a starting point for philosophical resolution (via logical analysis) for Carnap.

There are also reasons for resisting the idea that Carnap and Kuhn share a similar view of theory-choice. Kuhn's (1977) suggestion that paradigm choice inevitably involves the application of 'subjective' (i.e., non-shared) values is a conclusion that he reaches through an analysis of the history of science. Against philosophers who believe that theory-choice can be 'objective' by restricting theory-choice to the context of justification, Kuhn suggests that it is illegitimate to separate the contexts of discovery and justification. Kuhn (1977, pp. 326-329) complains that philosophical analyses that confine theory-choice to the context of justification 
systematically neglect factors that were historically regarded as relevant evidence and they tend to overemphasize arguments that supported the triumphant theory, while neglecting arguments that supported the losing theory. Thus, Kuhn's conclusion that theory-choice inevitable involves non-epistemic factors is inferred—in part—on the basis of historical analysis. By contrast, Carnap addresses questions regarding theory-choice exclusively in the context of justification. Moreover, while both Kuhn and Carnap can be said to share an instrumentalist (or pragmatic) stance on theory choice, ${ }^{8}$ Carnap's instrumentalism is far more robust. Consider differences between their views on the 'choice' between classical mechanics and relativistic physics. Whereas Kuhn ([1962] 1996, ch. 9) suggests that this was a forced choice between incommensurable paradigms that would define the field of physics, Carnap maintains that a decision can appeal to different purposes of physicists (Earman 1993, p. 22). On Carnap's view, each theory is useful for different purposes, e.g., classical mechanics is useful for purposes of measuring and making predictions about objects moving slower than $3 \times 10^{8} \mathrm{~m} / \mathrm{s}$, while relativistic mechanics is more useful for objects moving faster than $3 \times 10^{8} \mathrm{~m} / \mathrm{s}$. While Kuhn insists that this revolution was a case of relativistic physics replacing classical mechanics, Carnap adopts the more deflationary conventionalist stance that relativistic physics is an instrument that can be freely chosen on pragmatic grounds.

The aforementioned differences vitiate the argument that Carnap and Kuhn share a very similar view of scientific revolutions. While Carnap describes scientific revolutions in terms of a transition from one linguistic framework to another, it is crucial to see that Carnap's idea that a

\footnotetext{
${ }^{8}$ Kuhn ([1962] 1996, ch. 13, pp. 205-207) adopts an instrumentalist stance on theory-choice insofar as he suggests that, historically, paradigms that emerged as victors did so because they had greater puzzle-solving power, i.e., they could solve a significant number of puzzles of the previous paradigm and could also solve new puzzles (see Tsou 2006, pp. 216-217).
} 
revolution represents a pragmatic choice to adopt a new language is antithetical to Kuhn's view. Kuhn (2000) writes:

[T] he cognitive importance of language change was for [Carnap] merely pragmatic. One language might permit statements that could not be translated into another, but anything properly classified as scientific knowledge could be both stated and scrutinized in either language, using the same method and gaining the same result. . . This aspect of Carnap's position has never been available to me. Concerned ... with the development of knowledge, I have seen each stage in the evolution of a given field as built . . . upon its predecessors, the earlier stage providing the problems of the stage that followed. In addition, I have insisted that some changes in conceptual vocabulary are required for the assimilation and development of the observations, laws, and theories deployed in the later stage ... Given those beliefs, the process of transition from old state to new becomes an integral part of science, a process that must be understood . . . to analyze the cognitive basis for scientific beliefs. Language change is cognitively significant for me as it was not for Carnap. (pp. 227-228, emphasis added)

This passage indicates why Kuhn believes one cannot reduce a scientific revolution to a change in Carnapian linguistic frameworks. For Kuhn, the shift from one paradigm to another is not merely a pragmatic choice, but a naturalistic and historical process wherein scientists revise, assimilate, and respond to puzzles of the previous paradigm. From Kuhn's perspective, reducing revolutions to a Carnapian external question is to trivialize the problem of scientific change. To properly understand scientific development, one must historically analyze how new paradigms emerged out of old ones (Kuhn [1962] 1996, ch. 1). 


\section{Structure and the demise of logical empricism}

Reflections on Kuhn's and Carnap's contrasting approaches to philosophy of science help to clarify the historical role played by Kuhn's Structure in the decline of logical empiricism (cf. note 6). According to the analysis of this paper, Structure primarily contributed to the demise of logical empiricism by offering a concrete and fruitful example of a historically-oriented, bottomup methodology for philosophy of science that opposed to the top-down methodology associated with Carnap and the logical empiricists. This understanding provides reasons for rejecting Irzik and Grünberg's (1995, p. 304) contention that post-positivist philosophy of science associated with Kuhn does not represent a revolutionary departure from Carnapian philosophy of science.

The chief role that Structure played in the decline of logical empiricism and emergence of post-positivist philosophy of science was methodological. As discussed in section 4 of this paper, Carnap's logic of science adopts a top-down methodology insofar as it begins with certain a priori assumptions about what constitutes good science (e.g., science is non-metaphysical and empirical) and evaluates particular theories on the basis of these criteria. Kuhn's approach, by contrast, adopts a bottom-up methodology insofar as it begins with a historical examination of actual scientific practices and aims to draw philosophical conclusions about what constitutes good science via historical analysis. ${ }^{9}$ In this manner, Structure offered a novel method for analyzing science that significantly departed from the logical analyses championed by Carnap. By shifting the philosophical unit of analysis away from abstract scientific theories (in the

\footnotetext{
${ }^{9}$ Kuhn's bottom-up methodology can be understood as a particularist (as opposed to generalist) approach to philosophy of science. From this perspective, Structure can be located in a broader tradition of particularist approaches in philosophy (e.g., see Kant [1781] 1998; Wittgenstein [1953] 1958; Sellars [1956] 1997; McDowell 1979; Brandom 1994). For connections between Kuhn's and Wittgenstein's views, see Kindi $(1995,2012)$ and Sharrock and Reid (2002).
} 
context of justification) and towards historically-situated scientific theories (in the context of discovery), historical analysis—as exemplified in Structure — provided an alternative model for doing philosophy of science that would strongly influence subsequent generations of philosophers of science (and science studies more generally). ${ }^{10}$ Kuhn's bottom-up methodology opened avenues for more broadly-focused and interdisciplinary philosophical analyses, and especially analyses that were closely engaged with the history of science. In contrast to the formal analyses of concepts such as 'confirmation' and 'explanation' offered by logical empiricists, philosophical analyses inspired by Structure focused on a broader range of topics, such as the role of experiments in science (Hacking, 1983; Franklin 1986; Galison 1987; Chang 2004), the connections between conceptual development in science and research in cognitive science (Giere 1988; Thagard 1988, 1992; Andersen, Barker, \& Chen 2006), analogical and model-based reasoning in science (Hesse [1963] 1966; Magnani, Nersessian, \& Thagard 1999; Nersessian 2008), and the social dimensions of science (Hull 1988; Longino 1990, 2002; Douglas 2009; Wray 2011).

In addition to presenting an attractive alternative methodological approach for philosophers of science, Structure also contributed to the demise of logical empiricism—on a sociological level—by attacking a caricatured 'everyday image of logical positivism' and illegitimately associating it with the cumulative vision of scientific progress rejected in Structure

\footnotetext{
${ }^{10}$ In the 1960s and 1970s, Kuhn's Structure emerged as the most iconic and influential example of the new historical philosophy of science associated with writers such as Norwood Russell Hanson (1958), Stephen Toulmin (1961), Paul Feyerabend (1975), and Larry Laudan (1977). Retrospectively, these works have jointly been responsible for the 'historical turn' in philosophy of science (Bird 2008). In addition to its influence in philosophy of science, Structure had an arguably larger influence in the social sciences, especially among sociologists of science (see Bird 2000, ch. 7); Kuhn famously repudiated relativist interpretations of his work by proponents of the 'strong programme' of the sociology of scientific knowledge (Kuhn 2000, ch. 5).
} 
(Richardson 2007; Irzik 2012). ${ }^{11}$ While the picture of logical empiricism presented by Kuhn in Structure was vastly underdeveloped and ultimately misleading, the effect of his work was to stabilize and popularize a simplistic view of logical empiricism as a naïve brand of empiricist foundationalism (Richardson 2007, pp. 359-369), which Kuhn and subsequent philosophers of science could employ as foils for their own arguments. ${ }^{12}$ Hence, Structure also contributed to the demise of logical empiricism — and the rise of post-positivist philosophy of science—by promulgating and reifying a false image of logical empiricism.

At this point, what is correct and incorrect in the revisionist view can be stated with clarity. One of the motivations of the revisionist view is to urge that Carnap is a much more methodologically sophisticated philosopher of science than is typically thought and that many of alleged weaknesses of his view are simply misplaced. ${ }^{13} \mathrm{I}$ am largely sympathetic with this aspect of the revisionist argument. A large part of the narrative surrounding the received view on Carnap and Kuhn is that one of Kuhn's chief achievements in Structure was to demonstrate the methodological flaws of logical empiricism by highlighting the importance of issues such as the theory-ladenness of observation, the underdetermination of theories by evidence, and the nonepistemic aspects of science. The received view on Carnap and Kuhn is incorrect in assuming

\footnotetext{
${ }^{11}$ With characteristic honesty, Kuhn admitted that he had not read any of the mature works of Carnap when he was writing Structure (see Borradori [1991] 1994, p. 153; Kuhn 2000, p. 227, pp. 305-306; Irzik 2012, appendix). Wray (2013) points out that Kuhn likely did not feel the need to read later positivist works since he was well-acquainted with Quine's ([1951] 1980) critiques of Carnap, while Kuhn and Quine were colleagues at the Harvard Society of Fellows (see Kuhn 2000, p. 279).

${ }^{12}$ Besides Structure, Quine's influential criticisms of Carnap (Quine [1951] 1980, 1969) undoubtedly served to stabilize the image of logical empiricism as an impoverished project in empiricist foundationalism (see Reisch 2005, pp. 3-5). For criticisms of Quine's presentation of Carnap in the context of the Carnap-Quine analyticity debates, see Creath (1991), Stein (1992), and Friedman (1999, 2001).

${ }^{13}$ This aspect of the revisionist argument is part of the larger movement of historical scholarship on logical empiricism (e.g., see Coffa 1991; Cartwright, Cat, Fleck, \& Uebel 1996; Giere \& Richardson 1996; Nemeth \& Stadler 1996; Richardson 1998; Friedman 1999; Hardcastle \& Richardson 2003; Stadler 2003; Awodey \& Klein 2004; Okruhlik 2004; Reisch 2005; Carus 2007; Friedman \& Creath 2007; Richardson \& Uebel 2007; Uebel 2007; Creath, 2012), which has revealed both the great complexity of thought as well as heterogeneity within logical empiricism.
} 
that Carnap was unaware of or insensitive to these issues; in fact, many of Carnap's views were motivated by precisely these issues. Hence, the revisionist analysis is correct to point out that Carnap and Kuhn shared many of the same methodological assumptions and that there are similarities in the way that they understood the epistemological structure of scientific theories. However, the revisionist view is incorrect in drawing the stronger conclusion that Carnap's and Kuhn's shared assumptions render their philosophies closely aligned. I have argued that the similarities that revisionist analyses highlight are superficial. It is only by ignoring the fundamental differences in Carnap's and Kuhn's broader philosophical projects that this conclusion can be drawn.

The analysis of this paper also provides a corrective to the received view on the CarnapKuhn relationship. What is correct in the received view is that Kuhn's Structure ushered in a new style of doing philosophy of science, which significantly differed from Carnap's favored logical approach for analyzing science. Compared to Carnap, Kuhn's approach was characterized by a bottom-up approach to analyzing scientific theories and an emphasis on integrating the history of science into philosophical analyses. However, the received view is incorrect in maintaining Carnap's and Kuhn's views are diametrically opposed and that the primary achievement of Structure was to demonstrate the false assumptions of positivist philosophy of science. Rather, Kuhn's historical significance in the history of twentieth century philosophy of science was to change the focus of philosophy of science (e.g., from formal analyses to confirmation to issues concerning the nature of scientific change) and to change the favored methodological tools that philosophers of science employed to analyze science (i.e., from formal tools to historical resources). As I have argued, Kuhn's chief methodological achievement was to offer an alternative bottom-up and historical approach to analyzing scientific theories, which was 
opposed to the top-down and logical approach to analyzing theories championed by Carnap. In this sense, Structure undoubtedly represents a revolutionary departure from positivist philosophy of science, as exemplified in Carnap's work.

\section{Conclusion}

In this paper, I offered reasons for rejecting the conclusion that Carnap's and Kuhn's philosophies are closely aligned. In particular, I argued against the revisionist conclusions that Carnap and Kuhn share similar views on incommensurability, theory-choice, and scientific revolutions. Moreover, I argued that fundamental differences between their styles of philosophy of science pertained to their preferred methods of analyzing science (i.e., logical versus historical analysis), their stance on the context of discovery/ justification distinction, and the relative importance they place on accurately reconstructing science. According to this analysis, the primary role that Structure played in the demise of logical empiricism was to offer a novel bottom-up methodological approach for analyzing scientific theories that shifted subsequent generations of philosophers of science away from the top-down approach espoused by Carnap.

In the context of contemporary philosophy of science, Carnap and Kuhn can be regarded as model representatives of two distinctive traditions of doing philosophy of science. In the Carnapian tradition are philosophers whose analyses investigate science exclusively in the context of justification and favor formal methods. In the Kuhnian tradition are philosophers whose analyses are closely engaged with the history of science and aim to draw philosophical conclusions from historical case studies. While these two styles of philosophy of science need 
not be regarded as inherently incompatible, it is mistaken to think that these traditions spurned by Carnap and Kuhn do not constitute fundamentally different ways of doing philosophy of science.

\section{Acknowledgements}

I am grateful to Alan Richardson, Vasso Kindi, Christian Damböck, Trevor Pearce, Scott Edgar, Ian Hacking, Bill Wimsatt, Paul Hoyningen-Huene, Chris Pincock, Morgan Harrop, Philip Hanson, Gürol Irzik, George Reisch, Greg Frost-Arnold, David Marshall Miller, David Alexander, Uljana Feest, Thomas Uebel, and Matteo Collodel for helpful comments and suggestions. Earlier drafts of this paper were presented at the ninth biennial meeting of the International Society for the History of Philosophy of Science (HOPOS) at University of King's College, Halifax, NS, June 2012; the twenty-third biennial meeting of the Philosophy of Science Association (PSA) in San Diego, CA, November 2012; and the third annual Philosophy Alumni Conference at Simon Fraser University, Burnaby, BC, March 2013. I am grateful for feedback that I received on these occasions. Special thanks to Harrop (my commentator at the SFU alumni conference) for his detailed and extensive written comments. 


\section{References}

Andersen, H., P. Barker, \& Chen, X. (2006). The cognitive structure of scientific revolutions. Cambridge: Cambridge University Press.

Awodey, S., \& Klein, C. (Eds.) (2004). Carnap brought home: The view from Jena. Chicago: Open Court.

Axtell, G. S. (1993). In the tracks of the historicist movement: Re-assessing the Carnap-Kuhn connection. Studies in History and Philosophy of Science, 24(1), 119-146.

Bird, A. (2000). Thomas Kuhn. Princeton, NJ: Princeton University Press.

Bird, A. (2002). Kuhn's wrong turning. Studies in History and Philosophy of Science, 33(3), 443-463.

Bird, A. (2004). Kuhn, naturalism, and the positivist legacy. Studies in History and Philosophy of Science, 35(2), 337-356.

Bird, A. (2008). The historical turn in the philosophy of science. In S. Psillos \& M. Curd (Eds.), Routledge companion to the philosophy of science (pp. 67-77). Abingdon: Routledge.

Borradori, G. ([1991] 1994). The American philosopher: Conversations with Quine, Davidson, Putnam, Nozick, Danto, Rorty, Cavell, MacIntyre, and Kuhn (R. Crocitto, Trans.). Chicago: University of Chicago Press.

Brandom, R. B. (1994). Making it explicit: Reasoning, representing, and discursive commitment. Cambridge, MA: Harvard University Press.

Carnap, R. ([1931] 1959). The elimination of metaphysics through logical analysis of language. In A. J. Ayer (Ed.), Logical positivism (pp. 60-81). New York: The Free Press.

Carnap, R. ([1931] 1934). The unity of science (M. Black, Trans.). London: Kegan Paul, Trench Trubner and Co.

Carnap, R. ([1934] 1937). The logical syntax of language (A. Smeaton, Trans.). London: Kegan 
Paul, Trench Trubner and Co.

Carnap, R. (1936). Testability and meaning. Philosophy of Science, 3(4), 419-471.

Carnap, R. ([1936] 1949). “Truth and confirmation.” In H. Feigl \& Wilfrid Sellars (Eds.), Readings in philosophical analysis (pp. 119-127). New York: Appleton-Century-Crofts.

Carnap, R. (1937). Testability and meaning — continued. Philosophy of Science, 4(1), 1-40.

Carnap, R. ([1950] 1956). Empiricism, semantics, and ontology. In R. Carnap, Meaning and necessity: A study in semantics and modal logic, 2nd ed. (pp. 205-221). Chicago: University of Chicago Press.

Carnap, R. (1956). The methodological character of theoretical concepts. In H. Feigl \& M. Scriven (Eds.), The foundations of science and the concepts of psychology and psychoanalysis. Minnesota Studies in the Philosophy of Science, vol. 1 (pp. 3876). Minneapolis, MN: University of Minnesota Press.

Carnap, R. (1963). Replies and systematic expositions. In P. A. Schilpp (Ed.), The philosophy of Rudolf Carnap: Library of living philosophers, vol. 11 (pp. 859-1013). LaSalle, IL: Open Court.

Cartwright, N., Cat, J. Fleck, L., \& Uebel, T. E. (1996). Otto Neurath: Philosophy between science and politics. Cambridge: Cambridge University Press.

Carus, A. W. (2007). Carnap and twentieth-century thought: Explication as enlightenment. Cambridge: Cambridge University Press.

Chang, H. (2004). Inventing temperature: Measurement and scientific progress. Oxford: Oxford University Press.

Coffa, J. A. (1991). The semantic tradition from Kant to Carnap: To the Vienna station (L. Wessels, Ed.). Cambridge: Cambridge University Press.

Creath, R. (1991). Every dogma has its day. Erkenntnis, 35(1-3), 347-389.

Creath, R. (Ed.) (2012). Rudolf Carnap and the legacy of logical empiricism, Vienna Circle Institute Yearbook, vol. 16. Dordrecht: Springer.

Demopoulos, W. (2003). On the rational reconstruction of our theoretical knowledge. British 
Journal for the Philosophy of Science, 54(3), 371-403.

Demopoulos, W. (2007). Carnap on the rational reconstruction of scientific theories. In M.

Friedman \& R. Creath (Eds.), The Cambridge companion to Carnap (pp. 248-272).

Cambridge: Cambridge University Press.

DiSalle, R. (2002). Reconsidering Kant, Friedman, logical positivism, and the exact sciences. Philosophy of Science, 69(2), 191-211.

Douglas, H. E. (2009). Science, policy, and the value-free ideal. Pittsburgh, PA: University of Pittsburgh Press.

Earman, J. (1993). Carnap, Kuhn, and the philosophy of scientific methodology. In P. Horwich (Ed.), World changes: Thomas Kuhn and the nature of science (pp. 9-36). Cambridge, MA: MIT Press.

Feyerabend, P. K. (1970). Consolations for the specialist. In I. Lakatos \& A. Musgrave (Eds.), Criticism and the growth of knowledge (pp. 197-230). Cambridge: Cambridge University Press.

Feyerabend, P. K. (1975). Against method: Outline of an anarchistic theory of knowledge. London: New-Left Books.

Franklin, A. (1986). The neglect of experiment. Cambridge: Cambridge University Press.

Friedman, M. (1998). On the sociology of knowledge and its philosophical agenda. Studies in History and Philosophy of Science, 29(2), 239-271.

Friedman, M. (1999). Reconsidering logical positivism. Cambridge: Cambridge University Press.

Friedman, M. (2001). Dynamics of reason. Stanford, CA: CSLI Publications.

Friedman, M. (2003). Kuhn and logical empiricism. In T. Nickles (Ed.), Thomas Kuhn (pp. 1944). Cambridge: Cambridge University Press.

Friedman, M., \& Creath, R. (Eds.) (2007). The Cambridge companion to Carnap. Cambridge: Cambridge University Press. 
Galison, P. (1987). How experiments end. Chicago: University of Chicago Press.

Galison, P. L. (1995). Context and constraints. In J. Z. Buchwald (Ed.), Scientific practice: Theories and stories of doing physics (pp. 13-41). Chicago: University of Chicago Press. Gattei, S. (2008). Thomas Kuhn's “linguistic turn” and the legacy of logical empiricism: Incommensurability, rationality and the search for truth. Aldershot: Ashgate.

Giere, R. N. (1985). Philosophy of science naturalized. Philosophy of Science, 52(3), 331-356.

Giere, R. N. (1988). Explaining science: A cognitive approach. Chicago: University of Chicago Press.

Giere, R. N., \& Richardson, A. W. (Eds.) (1996). Origins of logical empiricism. Minnesota Studies in the Philosophy of Science, vol. 16. Minneapolis, MN: University of Minnesota Press.

Hacking, I. (1983). Representing and intervening: Introductory topics in the philosophy of science. Cambridge: Cambridge University Press.

Hanson, N. R. (1958). Patterns and discovery: An inquiry into the conceptual foundations of science. Cambridge: Cambridge University Press.

Hardcastle, G. L., \& Richardson, A. W. (Eds.) (2003). Logical empiricism in North America. Minnesota Studies in the Philosophy of Science, vol. 18. Minneapolis, MN: University of Minnesota Press.

Hempel, C. G. (1965). Empiricist criteria of cognitive significance: Problems and changes. In C. G. Hempel, Aspects of scientific explanation and other essays in the philosophy of science (pp. 101-119). New York: The Free Press.

Hesse, M. ([1963] 1966). Models and analogies in science, 2nd ed. Notre Dame, IN: University of Notre Dame Press.

Hoyningen-Huene, P. (1993). Reconstructing scientific revolutions: Thomas S. Kuhn’s philosophy of science (A. T. Levine, Trans.). Chicago: University of Chicago Press.

Hoyningen-Huene, P. (2006). Context of discovery versus context of justification and Thomas 
Kuhn. In J. Shickore \& F. Steinle (Eds.), Revisiting discovery and justification:

Historical and philosophical perspectives on the context distinction (pp. 119-131).

Dordrecht: Springer.

Hull, D. (1988). Science as a process: An evolutionary account of the social and conceptual development of science. Chicago: University of Chicago Press.

Irzik, G. (2002). Carnap and Kuhn: A belated encounter. In P. Gärdenfors, J. Woleński, \& K. Kijania-Placek (Eds.), In the scope of logic, methodology and philosophy of science, vol. 2 (pp. 603-620). Dordrecht: Kluwer.

Irzik, G. (2003). Changing conceptions of rationality: From logical empiricism to postpositivism. In P. Parrini, W. Salmon, \& M. H. Salmon (Eds.), Logical empiricism: Historical \& contemporary perspectives (pp. 325-346). Pittsburgh, PA: University of Pittsburgh Press.

Irzik, G. (2012). Kuhn and logical empiricism: Gaps, silences, and tactics in SSR. In V. Kindi \& T. Arabatzis (Eds.), Kuhn's The Structure of Scientific Revolutions revisited (pp. 15-40). New York: Routledge.

Irzik, G., \& Grünberg, T. (1995). Carnap and Kuhn: Arch enemies or close allies? British Journal for the Philosophy of Science, 46(3), 286-307.

Irzik, G., \& Grünberg, T. (1998). Whorfian variations on Kantian themes: Kuhn's linguistic turn. Studies in History and Philosophy of Science, 29(2), 207-221.

Jeffrey, R. (1994). Carnap's voluntarism. In D. Prawitz, B. Skyrms, \& D. Westersål (Eds.), Logic, methodology, and philosophy of science IX: Proceedings of the ninth International Congress of Logic, Methodology, and Philosophy of Science, Uppsala, Sweden, August 7-14, 1991 (pp. 847-866). Amsterdam: Elsevier.

Kant, I. ([1781] 1998). Critique of pure reason (P. Guyer \& A. W. Wood, Trans.). Cambridge: 
Cambridge University Press.

Kindi, V. P. (1995). Kuhn's The Structure of Scientific Revolutions revisited. General Journal for the Philosophy of Science, 26(1), 75-92.

Kindi, V. (2005). The relation of history of science to philosophy of science in The Structure of Scientific Revolutions and Kuhn's later philosophical work. Perspectives on Science, 13(4), 495-530.

Kindi, V. (2012). Kuhn's paradigms. In V. Kindi \& T. Arabatzis (Eds.), Kuhn's The Structure of Scientific Revolutions revisited (pp. 91-111). New York: Routledge.

Kuhn, T. S. ([1962] 1996). The structure of scientific revolutions, 3rd ed. Chicago: University of Chicago Press.

Kuhn, T. S. (1977). Objectivity, value judgment, and theory choice. In T. S. Kuhn, The essential tension: Selected studies in scientific tradition and change (pp. 320-339). Chicago: University of Chicago Press.

Kuhn, T. S. (2000). The road since structure: Philosophical essays, 1970-1993, with an autobiographical interview (J. Conant \& J. Haugeland, Eds.). Chicago: University of Chicago Press.

Lange, M. (2004). Review essay on Dynamics of reason by Michael Friedman. Philosophy and Phenomenology Research, 68(3), 702-712.

Laudan, L. (1977). Progress and its problems: Towards a theory of scientific growth. Berkeley, CA: University of California Press.

Longino, H. E. (1990). Science as social knowledge: Values and objectivity in scientific inquiry. Princeton, NJ: Princeton University Press.

Longino, H. E. (2002). The fate of knowledge. Princeton, NJ: Princeton University Press.

Magnani, L., Nersessian, N. J., \& Thagard, P. (Eds.) (1999). Model-based reasoning in scientific discovery. New York: Kluwer Academic/ Plenum Publishers. 
McDowell, J. (1979). Virtue and reason. The Monist, 62(3), 331-350.

McGuire, J. E. (1992). Scientific change: Perspectives and proposals. In M. H. Salmon et al., Introduction to the philosophy of science: A text by members of the department of history and philosophy of science of the University of Pittsburgh (pp. 132-178). Indianapolis, IN: Hackett.

Mladenović, B. (2007). "Muckraking in history": The role of the history of science in Kuhn's philosophy. Perspectives on Science, 15(3), 261-294.

Nemeth, E., \& Stadler, F. (Eds.) (1996). Encyclopedia and utopia: The life and work of Otto Neurath (1882-1945). Dordrecht: Kluwer.

Nersessian, N. J. (2008). Creating scientific concepts. Cambridge, MA: MIT Press.

Okruhlik, K. (2004). Logical empiricism, feminism, and Neurath's auxiliary motive. Hypatia, $19(1), 48-72$.

Pincock, C. (2012). Mathematics and scientific representation. Oxford: Oxford University Press.

Pinto de Oliveira, J. C. (2007). Carnap, Kuhn, and revisionism: On the publication of Structure in the Encyclopedia. Journal for General Philosophy of Science, 38(1), 147-157.

Preston, J. (2004). Bird, Kuhn, and positivism. Studies in History and Philosophy of Science, 35(2), 327-335.

Quine, W. V. ([1951] 1980). Two dogmas of empiricism. In W. V. Quine, From a logical point of view: Nine logico-philosophical essays, 2nd ed. (pp. 20-46). Cambridge, MA: Harvard University Press.

Quine, W. V. (1969). Epistemology naturalized. In W. V. Quine, Ontological relativity and other essays (pp. 69-90). New York: Columbia University Press.

Reisch, G. A. (1991). Did Kuhn kill logical positivism? Philosophy of Science, 58(2), 264-277.

Reisch, G. A. (2005). How the Cold War transformed philosophy of science: To the icy slopes of 
logic. Cambridge: Cambridge University Press.

Richardson, A. W. (1998). Carnap's construction of the world: The Aufbau and the emergence of logical empiricism. Cambridge: Cambridge University Press.

Richardson, A. W. (2002). Narrating the history of reason itself: Friedman, Kuhn, and a constitutive a priori for the twenty-first century. Perspectives on Science, 10(3), 253-274.

Richardson, A. (2007). "That sort of everyday image of logical empiricism": Thomas Kuhn and the decline of logical empiricist philosophy of science. In A. Richardson \& T. Uebel (Eds.), The Cambridge companion to logical empiricism (pp. 346-370). Cambridge: Cambridge University Press.

Richardson, A., \& Uebel, T. (Eds.) (2007). The Cambridge companion to logical empiricism. Cambridge: Cambridge University Press.

Sellars, W. ([1956] 1997). Empiricism and the philosophy of mind. Cambridge, MA: Harvard University Press.

Sharrock, W., \& Reid, R. (2002). Kuhn: Philosopher of scientific revolution. Cambridge: Polity Press.

Stadler, F. (Ed.) (2003). The Vienna Circle and logical empiricism: Re-evaluation and future perspectives. Vienna Circle Institute Yearbook, vol. 10. New York: Kluwer.

Stein, H. (1992). Was Carnap entirely wrong, after all? Synthese, 93(1-2), 275-295.

Suppe, F. ([1974] 1977). The search for philosophic understanding of scientific theories. In F. Suppe (Ed.), The structure of scientific theories, 2nd ed. (pp. 3-241). Urbana, IL: Illinois University Press.

Thagard, P. (1988). Computational philosophy of science. Cambridge, MA: MIT Press. Thagard, P. (1992). Conceptual revolutions. Princeton, NJ: Princeton University Press. Toulmin, S. (1961). Foresight and understanding: An enquiry into the aims of science. Bloomington, IN: Indiana University Press. 
Tsou, J. Y. (2003). Critical notice: A role for reason in science. Dialogue: Canadian Philosophical Review, 42(3), 573-398.

Tsou, J. Y. (2006). Genetic epistemology and Piaget's philosophy of science: Piaget vs. Kuhn on scientific progress. Theory \& Psychology, 16(2), 203-224.

Uebel, T. (2007). Empiricism at the crossroads: The Vienna circle's protocol sentence debate. Chicago: Open Court.

Uebel, T. (2011). Carnap and Kuhn: On the relation between the logic of science and the history of science. Journal for General Philosophy of Science, 42(1), 129-140.

Wittgenstein, L. ([1953] 1958). Philosophical investigations, 2nd ed. (G. E. Anscombe, Trans.). Oxford: Basil Blackwell.

Wray, K. B. (2011). Kuhn’s evolutionary social epistemology. Cambridge: Cambridge University Press.

Wray, K. B. (2013). Review of Vasso Kindi and Theodore Arabatzis (Eds.), Kuhn's The Structure of Scientific Revolutions revisited. Notre Dame Philosophical Reviews, 2013.03.13. Retrieved at: http://ndpr.nd.edu/news/38265-kuhn-s-the-structure-of-scientific-revolutions-revisited/ 